\title{
Miniaturized Band Notched UWB Antenna with Improved Fidelity Factor and Pattern Stability
}

\author{
Rajarshi SANYAL ${ }^{1}$, Partha P. SARKAR ${ }^{2}$, Santosh K. CHOWDHURY ${ }^{3}$ \\ ${ }^{1}$ Dept. of Electronics \& Communication Engineering, MCKV Inst. of Engineering, Howrah, W.B, India, \\ ${ }^{2}$ Dept. of Engineering and Technological Studies (DETS), University of Kalyani, Nadia, W.B, India, \\ ${ }^{3}$ Senior Member, IEEE, Kolkata W.B, India
}

rajarshi.sanyal1972@gmail.com, parthabe91@yahoo.co.in, santoshkumarchowdhury@gmail.com

Submitted January, 2017 / Accepted October 20, 2017

\begin{abstract}
This article presents a novel miniaturized monopole UWB antenna with enhanced band rejection characteristics at $5.5 \mathrm{GHz}$. The proposed configuration is derived from octagonal band notched UWB antenna which consists of $W$-shaped slotted ground plane and an open ended $\lambda_{\mathrm{g}} / 4$ hook shaped resonator as a band-notched element. By using proper miniaturization of the octagonal monopole and ground plane, 50\% reduction in main structure can be realized without changing the dimension of resonator. Frequency and time domain performance of the proposed miniaturized antenna design is compared with conventional half size and full size structures. The noticeable improvements in terms of band rejection characteristics, radiation pattern stability and fidelity factor confirm the effectiveness of the proposed miniaturization technique. Furthermore, the proposed antenna provides much wider operating bandwidth $(V S W R<2)$ within $3.1-17.2 \mathrm{GHz}$ with the exception around 5-6 GHz.
\end{abstract}

\section{Keywords}

Miniaturized antenna, ultra wideband (UWB), radiation pattern stability, fidelity factor

\section{Introduction}

In recent year ultra wide band (UWB) communication system becomes popular among the researchers after the allocation of commercial UWB frequency band of $3.1-10.6 \mathrm{GHz}$ by federal communication commission (FCC) [1]. However, UWB system will cause interference to the existing narrow band systems such as WIMAX system at $3.5 \mathrm{GHz}(3.3-3.7 \mathrm{GHz})$ and WLAN system at $5.5 \mathrm{GHz}(5-6 \mathrm{GHz})$ so that different band rejection element may be employed in the antenna itself to minimize the interference. Different band rejection UWB antenna have been reported earlier [2-8].Miniaturization of antenna is another important issue in current research work. In previous literature several miniaturization techniques of
UWB antenna have been discussed and their frequency and time domain performance have been analyzed [9-12]. Works on half area reduction of the symmetrical UWB antenna with or without band notch using conventional halving technique have also been reported in most of the literatures which provide straightforward miniaturization technique [12-15]. Conventional half reduction uses the mechanism of simple exploitation of structural symmetry. By proposing a common feeding technique and chopping the symmetrical monopole antenna structure into halves along the magnetic symmetry line of the antenna, better impedance bandwidth can be obtained in UWB antenna [13], [14]. Better time domain performance has also been reported in recent literature for miniaturized UWB antenna [15].

In this paper the frequency and time domain performances of the proposed miniaturized band notched UWB antenna have been discussed. Main focus of this paper is to establish the advantage of proposed reduction mechanism on to the conventional reduction in presence of band notch function. Conventional halving technique gives rise to a perturbation in surface current density and presence of band rejection element leads to enhanced rejection at notched bands. However, stronger notch function will result in more destructive interference which in turn degrades the fidelity. The distinctive feature of proposed miniaturization mechanism is the significant improvement in fidelity factor as well as enhanced band rejection. In proposed technique optimized miniaturization in patch and ground plane also provide $50 \%$ area reduction in full size band notched UWB antenna. Moreover the additional advantage of the proposed reduced band notch UWB is the radiation pattern stability improvement over UWB frequency range.

The paper is organized as follows. Initially an octagonal band notched UWB antenna has been designed where quarter wavelength open hook shaped slot resonator has been on the one side of the patch surface which is referred to as full size Non symmetric structure. For the symmetrical Full size band notched structure, a hook shaped resonator pair is embedded to the UWB antenna in next devel- 
opment. Further the Symmetrical full structure is reduced to conventional half size structure and the proposed miniaturized structure in next steps. In Sec. 3, the frequency domain and time domain performances of the full size (Non-symmetrical and symmetrical), conventional half size and proposed miniaturized antenna are compared and effectiveness of the proposed structure has been analyzed. A brief comparative study is prepared between the conventional half structure as mentioned in previous literature and the proposed miniaturized structure to illustrate its potential. Finally, this paper is concluded in the last section.

\section{Design of Band-notched UWB Antenna and Its Miniaturization}

Figure 1(a) illustrates full size printed octagonal monopole antenna with $\mathrm{W}$ shaped truncation on ground plane which is constructed on Rogers 5870 substrate. The thickness of substrate is $1.6 \mathrm{~mm}$ and the relative permittivity is 2.33. The dimension of full size structure is $36.6 \times 26 \mathrm{~mm}^{2}$. An open ended quarter wavelength band rejection element has been incorporated to one side of octagonal patch surface to obtain band rejection at 5.5 GHz. The optimized length of hook-shaped open ended slotted resonator can be empirically optimized as

$$
X_{1}+X_{2}+X_{3}+X_{4}+X_{5}-4 t=L_{\mathrm{n}}=\frac{c}{4 f_{\mathrm{n}} \sqrt{\varepsilon_{\mathrm{reff}}}}
$$

where $\varepsilon_{\text {reff }}=\left(\varepsilon_{\mathrm{r}}+1\right) / 2, c$ is velocity of light, $\varepsilon_{\mathrm{r}}$ is relative permittivity of the substrate.

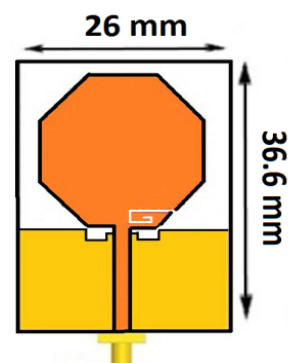

(a)

$13.6 \mathrm{~mm}$

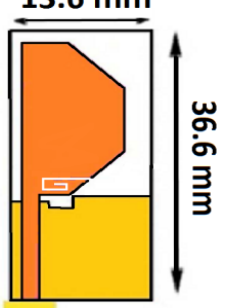

(c)

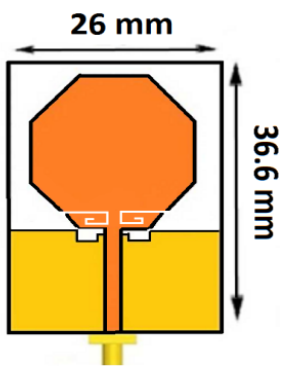

(b)

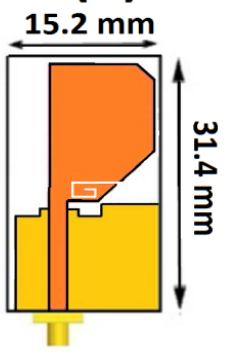

(d)
Fig. 1. Antennas: (a) Full size non-symmetrical band notched UWB. (b) Full size symmetrical band notched UWB (c) Conventional half size band notched UWB. (d) Proposed miniaturized band notched UWB.

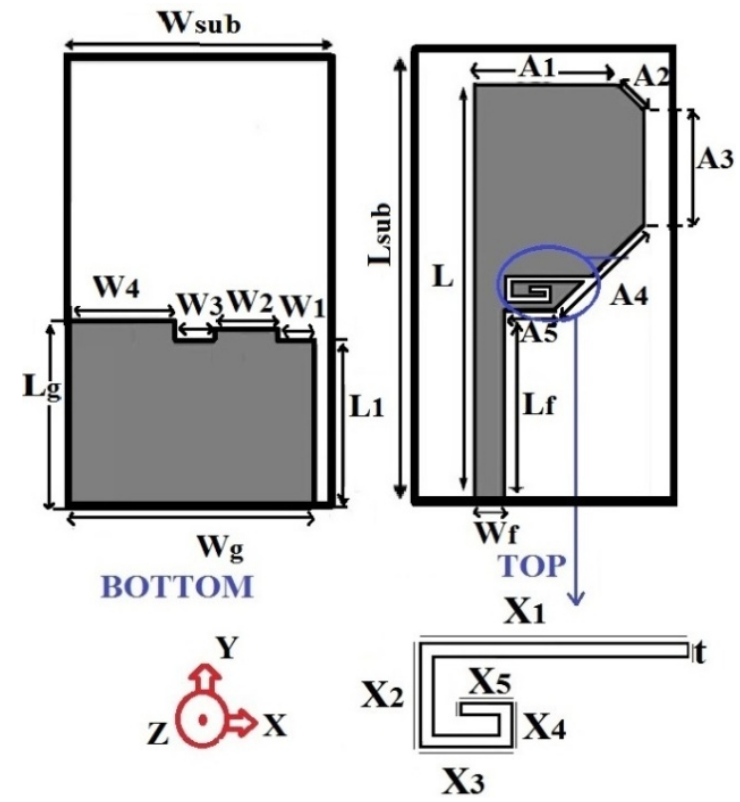

Fig. 2. Geometry and dimension of the proposed miniaturized band notched UWB antenna.

An antenna with one sided resonator is basically a nonsymmetric full structure. Insertion of similar resonator pair on the both side of the patch surface makes the band notched UWB antenna a perfect symmetrical full structure as shown in Fig. 1(b). Conventional half size antenna is designed by exploiting the symmetry of radiator and the ground plane. By using the aforementioned conventional halving method, $48 \%$ reduction in full size area can be achieved as shown in Fig. 1(c). In this way original full size antenna is simply halved while keeping the patch and ground plane structure symmetrical. However, the remaining part of conventional half size antenna consists of quarter wave length hook-shaped band-notched element. The dimension of conventional half size antenna is $36.6 \times 13.6 \mathrm{~mm}^{2}$. Since there is no change in the effective length of half size antenna, it does not affect too much on lower operating frequency. The proposed miniaturized structure has been designed by using the proper reduction of length and width of the radiating element and ground plane. The proposed miniaturized band notched UWB antenna has overall dimension of $31.4 \times 15.2 \mathrm{~mm}^{2}$. In present technique, length of the patch is further reduced while the width of the ground plane is widened towards the truncated part as shown in Fig. 1(d). The length of the ground plane affects impedance matching more significantly at higher frequencies rather than that at lower frequencies.

Actually at higher frequency, current concentration in ground plane becomes stronger; hence multiple truncations on the upper edge of the ground plane contribute towards better impedance matching which in turn suppresses the negative effect of the ground plane at higher frequencies. However, the reduced patch length is sensitive to the low frequency limit and hence the optimized patch length in the proposed antenna has been optimized in such a way that it covers the UWB frequency band. On the basis of the above design consideration, the geometry and prototype of the 


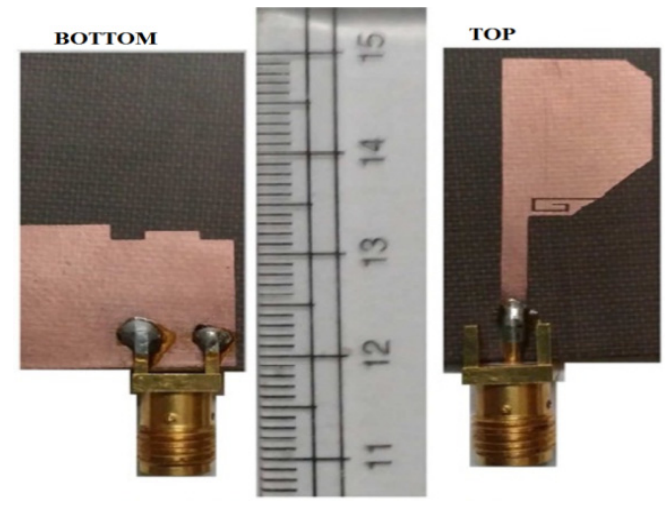

Fig. 3. Photograph of the fabricated proposed miniaturized band notched UWB antenna.

\begin{tabular}{|c|c|c|c|}
\hline Parameter & Dimension [mm] & Parameter & Dimension [mm] \\
\hline $\mathrm{W}_{\text {sub }}$ & 15.2 & $\mathrm{~L}_{2}$ & 0.8 \\
\hline $\mathrm{L}_{\text {sub }}$ & 31.4 & $\mathrm{~L}_{3}$ & 0.8 \\
\hline $\mathrm{L}_{\mathrm{g}}$ & 14 & $\mathrm{~L}_{4}$ & 1.5 \\
\hline $\mathrm{W}_{\mathrm{g}}$ & 15.2 & $\mathrm{~A}_{5}$ & 3.3 \\
\hline $\mathrm{A}_{1}$ & 9.1 & $\mathrm{~L}$ & 13.98 \\
\hline $\mathrm{A}_{2}$ & 2.8 & $\mathrm{~L}_{\mathrm{f}}$ & 1.86 \\
\hline $\mathrm{A}_{3}$ & 8.4 & $\mathrm{~W}_{\mathrm{f}}$ & 5.36 \\
\hline $\mathrm{A}_{4}$ & 8.4 & $\mathrm{t}$ & 0.5 \\
\hline $\mathrm{L}_{1}$ & 12.5 & $\mathrm{~W}_{1}$ & 2.5 \\
\hline $\mathrm{W}_{2}$ & 4 & $\mathrm{X}_{2}$ & 1.8 \\
\hline $\mathrm{W}_{3}$ & 2.5 & $\mathrm{X}_{3}$ & 2.8 \\
\hline $\mathrm{W}_{4}$ & 8.5 & $\mathrm{X}_{4}$ & 1 \\
\hline $\mathrm{X}_{1}$ & 5.36 & $\mathrm{X}_{5}$ & 1.3 \\
\hline
\end{tabular}

Tab. 1. Optimized parameter values of the proposed antenna shown in Fig. 2.

proposed miniaturized band notched UWB antenna have been illustrated in Fig. 2 and Fig. 3 correspondingly and the optimized dimension of parameters of the proposed antenna is summarized in Tab. 1.

\section{Results and Discussion}

\subsection{Antenna Miniaturization Effect on Band Rejection Characteristics}

Figure 4 illustrates simulated and measured VSWR characteristics of the proposed antenna (predicted by HFSS simulator). The size reduction of full size symmetrical octagonal band-notched UWB antenna yields for two new structures: one is conventional half size band-notched UWB antenna and another is the proposed miniaturized structure. For full size band notched non-symmetrical or symmetrical structure, current flows along current paths of different lengths. Due to the longer radiating current path, the surface current concentration around band notch element does not create much influence at the stop band in full size non-symmetrical structure. However, in full size symmetrical structure, a pair of hook shaped resonators has strong rejection effect which enhances the rejection per-

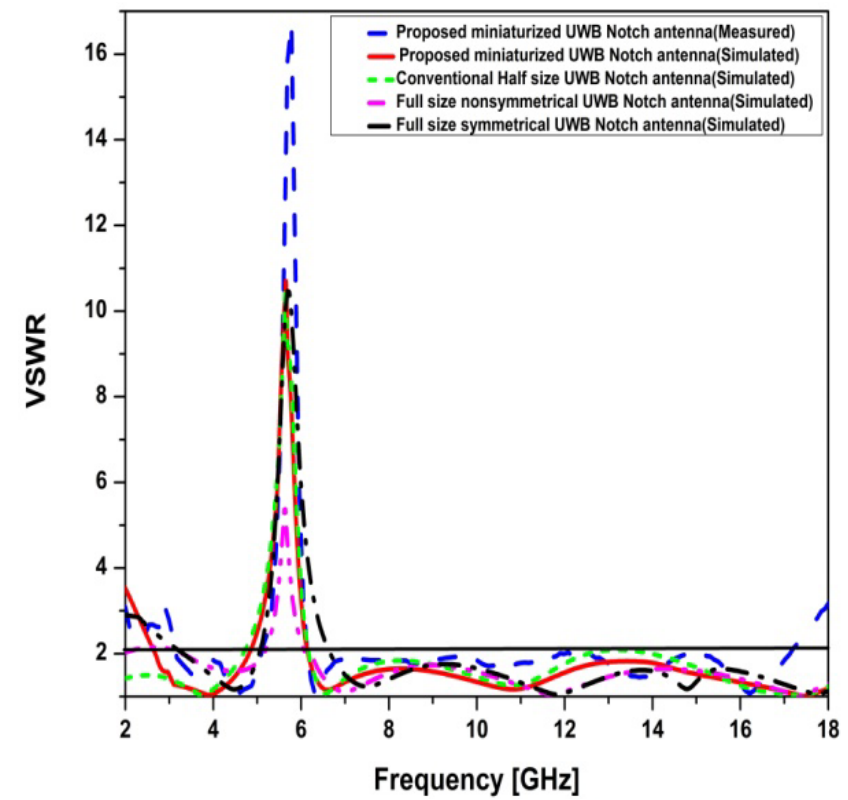

Fig. 4. VSWR characteristics for different structures.

formance almost double. The simulated VSWR performance of full size non-symmetric structure exhibits frequency rejection in the frequency band $5.3-6 \mathrm{GHz}$ with peak VSWR of 4.1 only at $5.5 \mathrm{GHz}$. On the other hand, full size symmetric structure has wide rejection band (5.2 to $6.5 \mathrm{GHz}$ ) with simulated peak VSWR of 10.1. For conventional half size, asymmetrical shape of patch changes the current distribution of the radiating path. Due to the reduction in effective current path, reduced patch surface area accumulates more current and the presence of resonator on that part of the patch surface creates enhanced perturbation which occurs due to the maximum surface current concentration around the band notched element which improves the rejection at $5.5 \mathrm{GHz}$ with simulated peak VSWR of 9 . For the proposed miniaturized structure, patch length reduction creates more compact patch size and as a result, deep band notch of simulated VSWR of 10.2 at $5.5 \mathrm{GHz}$ is obtained. The measured VSWR of the fabricated prototype covers the impedance bandwidth $3.1-17.2 \mathrm{GHz}$ (VSWR $<2$ ) with notch band $5.1-6 \mathrm{GHz}$ for WLAN system. The discrepancy in VSWR between simulated and measured results may be attributed to the fabrication tolerance. Quality factor is another focusing issue in band rejection mechanism. Though simulated peak VSWR performance of the symmetrical full structure and the proposed miniaturized structure are same, it is observed that the sharper rejection band of the proposed miniaturized antenna leads to improved quality factor of rejection band.

\subsection{Antenna Miniaturization Effect on Radia- tion Pattern Stability}

Radiation properties of the miniaturized monopole antenna are compared with the conventional half size structure, full size symmetric and full size non-symmetric structure. Figure 5 and Figure 6 illustrate the normalized co-polar radiation pattern of four antennas at $4 \mathrm{GHz}$, 
6.5 GHz, $9 \mathrm{GHz}$ and $11 \mathrm{GHz}$ in X-Y plane and X-Z plane correspondingly. The $\mathrm{X}-\mathrm{Y}$ plane pattern of full size symmetric and non-symmetric structures clearly shows the deep null at $\theta=90^{\circ}$ for different frequencies, especially sharp decline at high frequency. The conventional half size design still has the worst angular performance at $\theta=90^{\circ}$ but the average null magnitude difference between the conventional half structure and the full size non-symmetric structure is $7.5 \mathrm{~dB}$ and approximately $9.2 \mathrm{~dB}$ difference with the full size symmetric structure. On the other hand, the patterns of the proposed miniaturized structure have maximum average null difference $(12 \mathrm{~dB})$ in comparison to the full size non-symmetric and $14 \mathrm{~dB}$ with the symmetric full size structure. Similarly in X-Z plane (as shown in Fig. 6), large turbulence in patterns can be observed in full structures. Patterns of half structure still fluctuate mainly at higher frequencies. But in the proposed miniaturized structure, co-polarized patterns are relatively more stable. In full size structures; the surface current is not uniformly distributed. At higher frequency, full size structures more likely encounter inverse current which affects radiation pattern stability significantly. By using proper miniaturization, the balance between horizontal and vertical surface current of the patch can be obtained. Since width difference between the patch and the ground plane is an important factor for the uniformity of co-polarization patterns, more stable radiation pattern at high frequency can be achieved as the ground plane width is considered to be greater than the effective patch width in the proposed miniaturized antenna. However with increasing ground plane width, impedance matching characteristics are degraded which can be compensated by the multiple etched slots on the upper edge of the ground plane.

Figure 7 illustrates measured co-polarized radiation patterns of the proposed miniaturized structure for azimuth
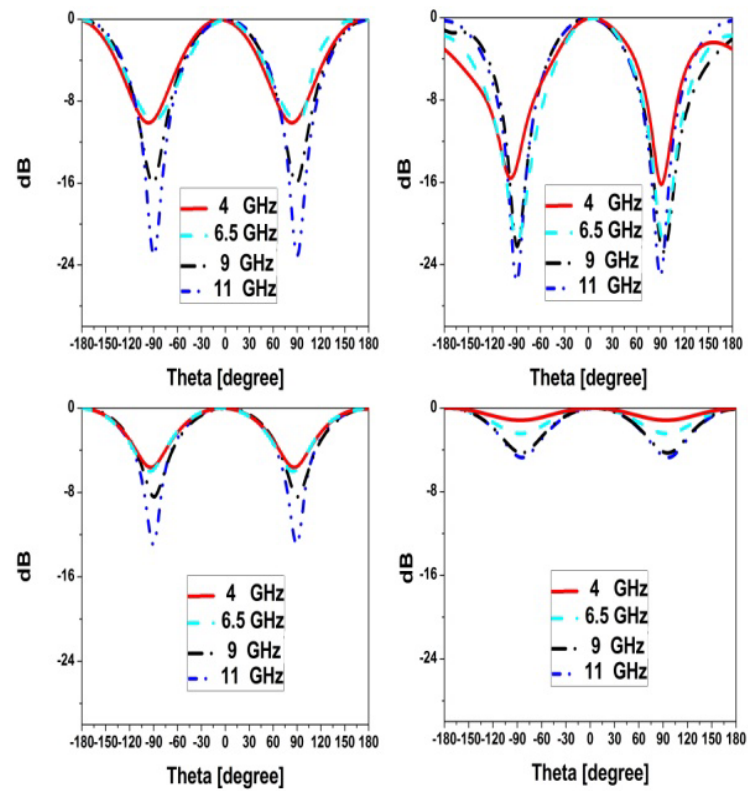

Fig. 5. Simulated elevation $(\mathrm{XY})$ plane radiation pattern for: (a) full size non-symmetric structure, (b) full size symmetric structure, (c) conventional half structure, (d) the proposed miniaturized structure.

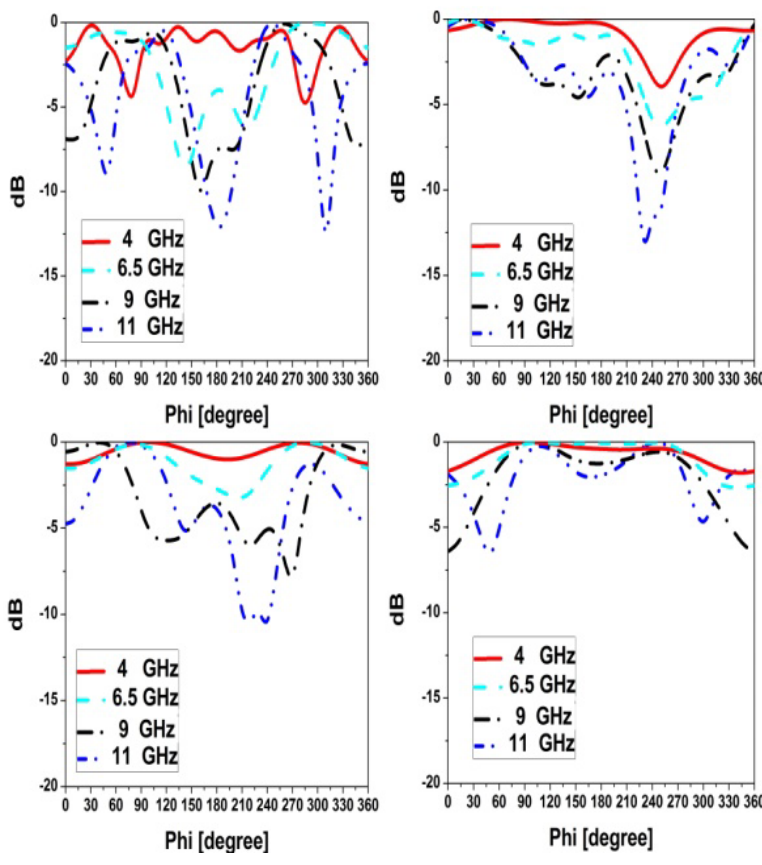

Fig. 6. Simulated azimuth (XZ) plane radiation pattern for: (a) full size non-symmetric structure, (b) full size symmetric structure, (c) conventional half structure, (d) the proposed miniaturized structure.
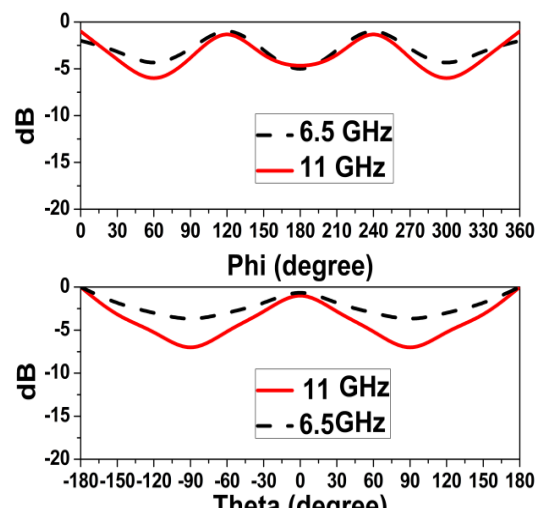

Fig. 7. Measured radiation pattern for the proposed miniaturized antenna for (a) azimuth (XZ) plane, and (b) elevation (XY) plane.

and elevation planes. The measured results of Fig. 7 are in good agreement with the simulated results as shown in Fig. 5(d) and Fig. 6(d).

\subsection{Antenna Miniaturization Effect on Fidel- ity Factor}

In order to verify the time domain performance, fidelity factor plays an important role. It is a normalized correlation coefficient between the Gaussian excitation pulse $x(t)$ and the radiated pulse in different direction $Y_{\theta, \varphi}(t)$. Fidelity Factor $F F(\theta, \varphi)$ is given by

$$
F F(\theta, \varphi)=\max _{\tau}\left(\frac{\int X(t) \cdot Y_{\theta, \varphi}(t-\tau) \mathrm{d} t}{\sqrt{\int X^{2}(t) \mathrm{d} t} \sqrt{\int Y_{\theta, \varphi}^{2}(t) \mathrm{d} t}}\right) .
$$


In this paper, the fifth derivative of the Gaussian pulse is assumed as an excitation pulse as shown in Fig. 8. Figure 9 and 10 illustrate the normalized electric field for the different location of virtual probe in elevation $(\mathrm{X}-\mathrm{Y})$ plane and azimuth $(X-Z)$ plane for the full size non-symmetric, full size symmetric, conventional half size and proposed miniaturized structures. Pulse preserving capability of the conventional half size structure is worst where the dispersion of pulse can be clearly observed in X-Z plane for the half size structure. Similarly in the symmetrical full size structure, more pronounced ringing effect especially for the lower angle is produced due to the presence of two resonators. On the contrary, the proposed miniaturized structure has a low level of distortion. Similarly in X-Y plane, the intense fluctuation in amplitude can be observed with decreasing value of $\theta$ for the conventional half size structure and also the higher time dispersion can be observed in the full size symmetrical structure with increasing value of $\theta$ while it becomes smaller in the proposed miniaturized antenna with negligible ringing at trailing edge.

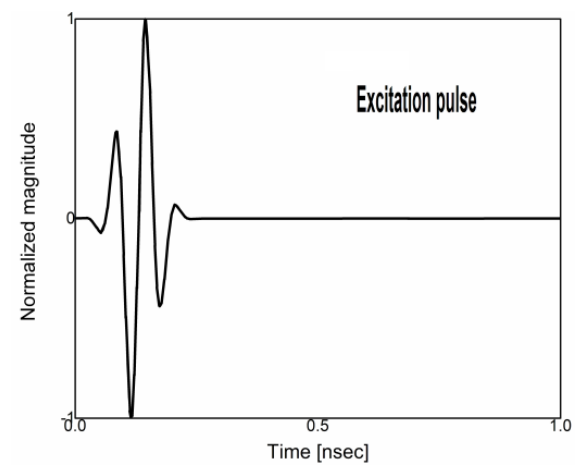

Fig. 8. Gaussian normalized input pulse.
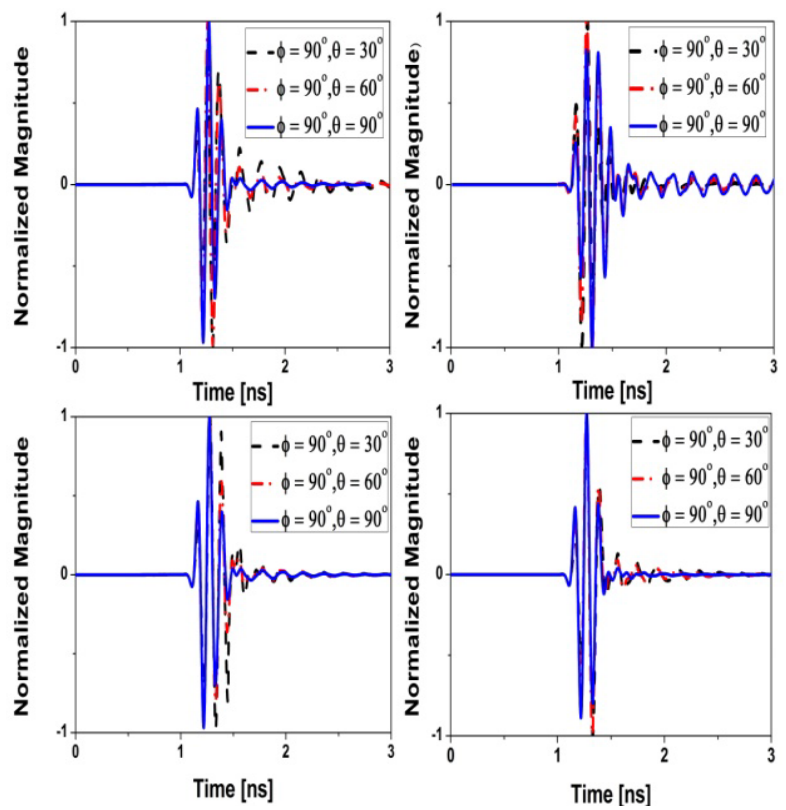

Fig. 9. Received signals (XY-plane) by the virtual probes for (a) non-symmetrical full structure, (b) symmetrical full structure, (c) conventional half structure, (d) proposed miniaturized structure.
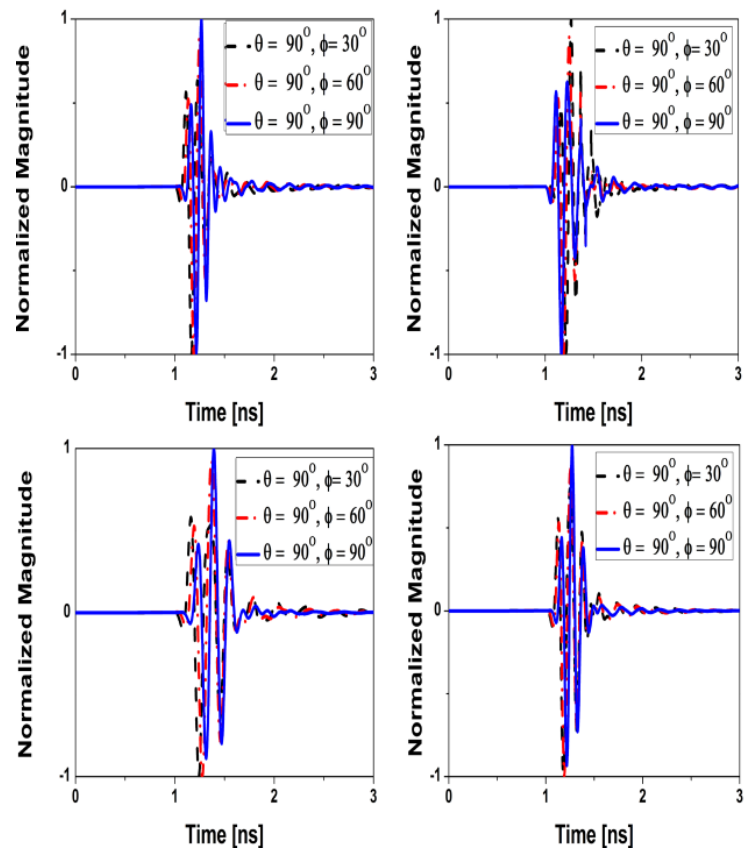

Fig . 10. Received signals (XZ-plane) by the virtual probes for (a) non-symmetrical full structure, (b) symmetrical full structure, (c) conventional half structure, (d) proposed miniaturized structure.

Fidelity factor is plotted for all four structures for elevation (X-Y) and azimuth (X-Z) planes as shown in Fig. 11 and Fig. 12, respectively. The average fidelity factors are summarized in Tab. 2 which reveals the advantage of half size. The hypothesis behind this can be explained as follows. There is a trade-off between quality of notch rejection and time domain performance. Hence poor fidelity factor of the conventional half size band notch structure is mainly due to the negative influence of enhanced notch performance.

Another reason for degraded fidelity factor is the asymmetrical shape of the conventional half size structure. On the other hand, fidelity factor of the symmetrical full

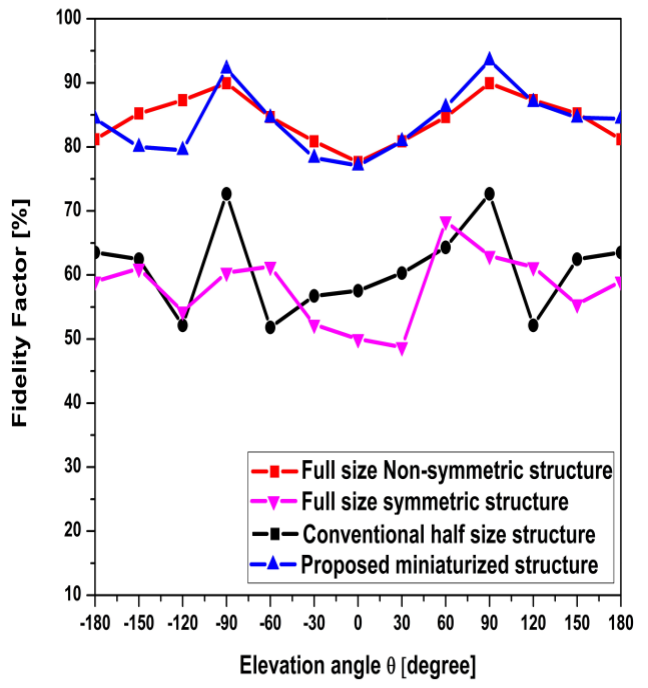

Fig. 11. Fidelity factor in elevation $(\mathrm{XY})$ plane for different values of the elevation angle $\theta$. 


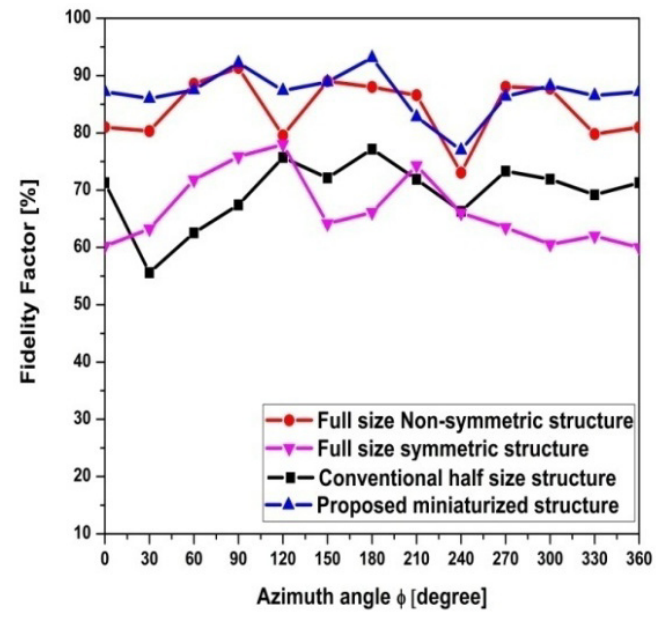

Fig. 12. Fidelity factor in azimuth (XZ) plane for different values the azimuth angle $\varphi$.

\begin{tabular}{|l|c|c|}
\hline \multicolumn{1}{|c|}{ Antenna structure } & $\begin{array}{c}\text { Fidelity Factor in } \\
\text { azimuth plane [\%] }\end{array}$ & $\begin{array}{c}\text { Fidelity Factor in } \\
\text { elevation plane[\%] }\end{array}$ \\
\hline Full size non-symmetrical & 84.15 & 84.31 \\
\hline Full size symmetrical & 69.33 & 59.45 \\
\hline Conventional half size & 66.56 & 60.89 \\
\hline Proposed miniaturized & 86.18 & 84.82 \\
\hline
\end{tabular}

Tab. 2. Average fidelity factor of different antenna structure in azimuth and elevation plane.

size structure is also deteriorated due to the presence of band notched element pair. However fidelity factor of the proposed miniaturized structure improves significantly when an abrupt geometric feature of conventional half size antenna is reconfigured.

\subsection{Tuning Characteristics of Rejection Band}

Figure 13 illustrates the tuning characteristics of the proposed miniaturized antenna around other WLAN narrowband frequencies such as $2.4,3.6$ and $5.2 \mathrm{GHz}$. Using the arm length variation of open ended hook shaped resonator, notched band can be swept over a wide frequency range and targeted rejection bands can be achieved. As the effective length of the resonator increases, the rejection band shifts towards the lower frequency band.

\subsection{Surface Current Distribution}

Figure 14 illustrates the simulated surface current distribution of proposed miniaturized antenna at $5.5 \mathrm{GHz}$ where a large current concentration around the hookshaped resonator is observed.

\subsection{Measured Peak Gain}

Figure 15 illustrates the measured peak gain of the proposed miniaturized antenna. The average peak gain is 2 $\mathrm{dBi}$ throughout the whole operating band except around the rejection band of 5-6 GHz where the peak gain can be as low as $-5 \mathrm{dBi}$.

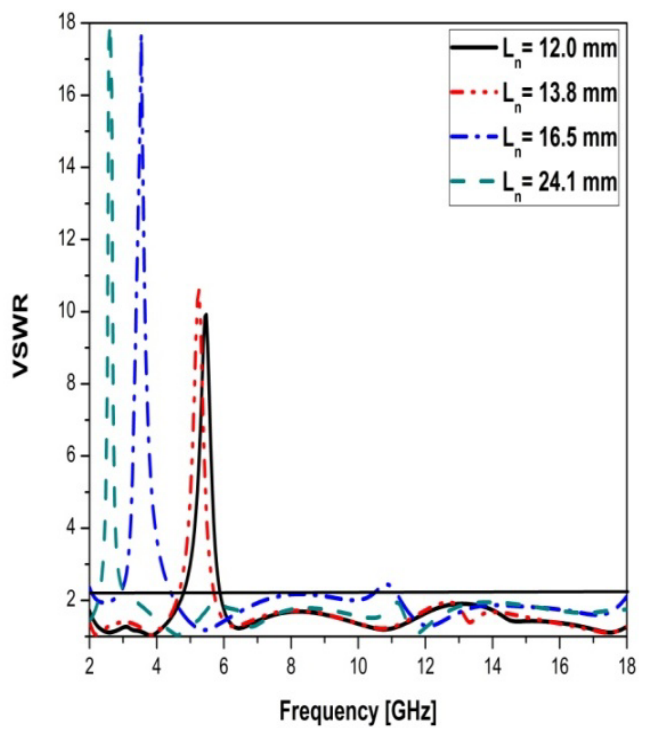

Fig. 13. Simulated VSWR for different values of effective length of the resonator.

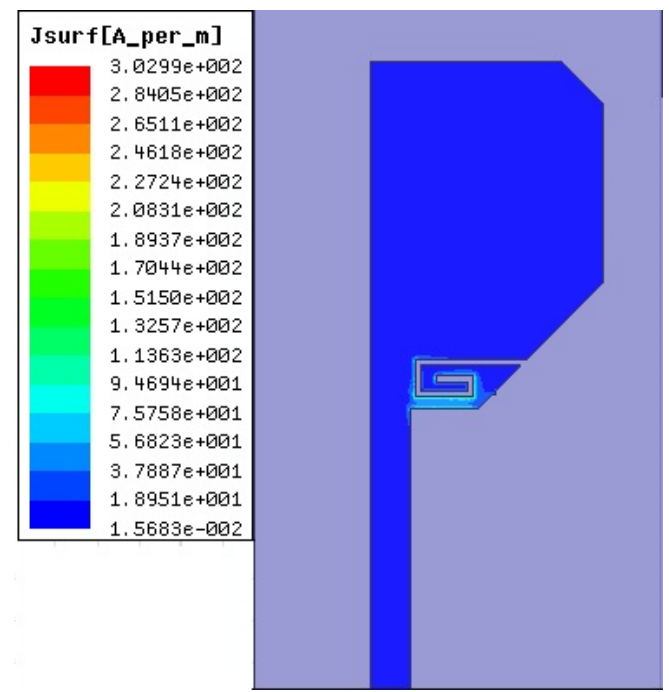

Fig. 14. Simulated result of current distribution at the rejection band frequency of $5.5 \mathrm{GHz}$.

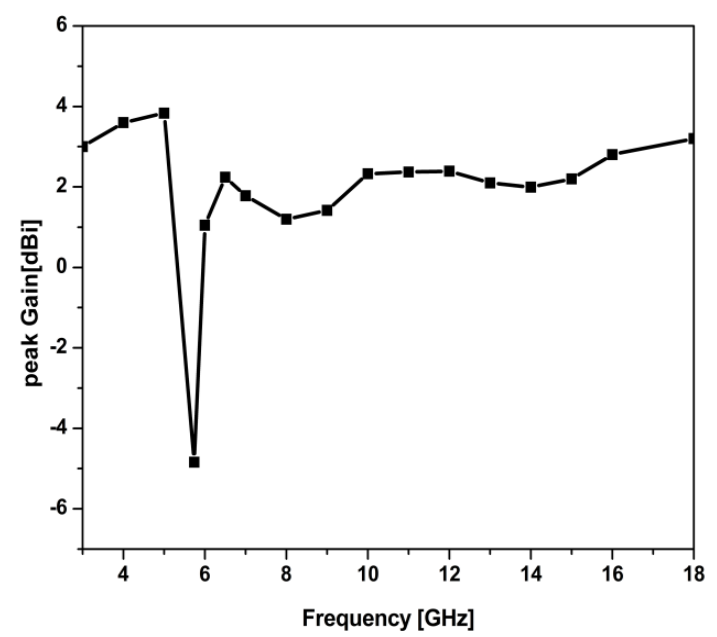

Fig. 15. Measured peak gain of the proposed miniaturized antenna. 


\begin{tabular}{|c|c|c|}
\hline Antenna & $\begin{array}{c}\text { Conventional half } \\
\text { UWB band notched } \\
\text { antenna [13] }\end{array}$ & $\begin{array}{c}\text { Proposed miniaturized } \\
\text { band notched UWB } \\
\text { antenna }\end{array}$ \\
\hline Size reduction [\%] & 50 & 50 \\
\hline Created notch & $\begin{array}{c}\text { Single } \\
\text { (fixed at 5.5 GHz) }\end{array}$ & $\begin{array}{c}\text { Single (with tuning facility } \\
\text { at 2.4, 3.6, 5.2 and 5.5 GHz) }\end{array}$ \\
\hline $\begin{array}{c}\text { Quality factor } \\
\text { of notched band }\end{array}$ & 3.24 & 6.17 \\
\hline $\begin{array}{c}\text { Radiation pattern } \\
\text { stability improve- } \\
\text { ment at elevation } \\
\text { plane [\%] }\end{array}$ & 84.65 & 88.39 \\
\hline
\end{tabular}

Tab. 3. Summary of the comparative studies between the conventional half band notched UWB antenna and the proposed miniaturized band notched UWB antenna.

Table 3 summarizes the comparisons of performance investigation and size reduction results of the proposed miniaturized antenna with the conventional half antenna as referred in [13]. In spite of similar percentage area reduction of both, some distinct advantage of the proposed miniaturized antenna is seen over the conventional half antenna irrespective to notched frequency tuning characteristics, rejection band quality factor and radiation pattern stability. On the basis of the above investigation and comparison, it may be concluded that our proposed miniaturization technique is more effective.

\section{Conclusion}

A miniaturized UWB band notched antenna has been designed and investigated. A novel reduction technique has been adopted for remarkable area reduction of $50 \%$ in regular octagonal band notched UWB antenna by keeping the length and the size of the open ended quarter wavelength hook-shaped band notched element is fixed. The proposed structure is compared with another reduced established structure made by conventional halving technique and full structure. The proposed antenna demonstrates significant performance improvement in band rejection, radiation pattern stability and fidelity factor. Moreover, very wide impedance bandwidth $(3.1-17.2 \mathrm{GHz})$ makes the proposed small antenna as a very good candidate for future UWB applications.

\section{References}

[1] FEDERAL COMMUNICATION COMMISSION. First Report and Order, Revision of Part 15 of the Commission's Rule Regarding Ultra-Wideband Transmission System FCC 02-48. 2002.

[2] BAHADORI, K., RAHMAT-SAMII, Y. A miniaturized ellipticcard UWB antenna with WLAN band rejection for wireless communications. IEEE Transaction on Antennas and Propagation, 2007, vol. 55, no. 11, p. 3326-3332. DOI: 10.1109/TAP.2007.908800

[3] MAMdOUH, M., ALI, M., SAAD, A. A., et al. A design of miniaturized ultra-wideband printed slot antenna with $3.5 / 5.5 \mathrm{GHZ}$ dual band-notched characteristics: analysis and implementation. Progress In Electromagnetics Research B, 2013, vol. 52, p. 37-56. DOI: 10.2528/PIERB 13041303

[4] ABDEL-HAMEED, A. S., SALEM, D., ABDALLAH, E. A., et al. Quasi self-complementary UWB notched microstrip antenna for USB application. Progress In Electromagnetics Research B, 2013, vol. 56, p. 185-201. DOI: 10.2528/PIERB13040807

[5] SIDDIQUI, J. Y., SAHA, C., ANTAR, Y. M. M. Compact SRR loaded UWB circular monopole antenna with frequency notch characteristics. IEEE Transactions on Antennas and Propagation, 2014, vol. 62, no. 8, p. 4015-4020. DOI: 10.1109/TAP.2014.2327124

[6] KANG, L., LI, H., WANG, X.-H., et al. Miniaturized bandnotched UWB MIMO antenna with high isolation. Microwave and Optical Technology Letters, 2016, vol. 58, no. 4, p. 878-881. DOI: 10.1002/mop.29691

[7] WU, Z.-H., WEI, F., SHI, X.-W., et al. A compact quad band notched UWB monopole antenna loaded one lateral L-shaped slot. Progress In Electromagnetics Research, 2013, vol. 139, p. 303-315. DOI: 102528/PIER13022714

[8] XIE, M., GUO, Q., WU, Y. Design of a miniaturized UWB antenna with band-notched and high frequency rejection capability. Journal of Electromagnetic Waves and Applications, 2011, vol. 25 , no. 8-9, p. 1103-1112. DOI: $10.1163 / 156939311795761999$

[9] CHEN, Z. N., TERENCE, S. P. S., QING, X. Small printed ultrawideband antenna with reduced ground plane effect. IEEE Transactions on Antennas and Propagation, 2007, vol. 55, no. 2, p. 383-388. DOI:10.1109/TAP.2006.889823

[10] ZHOU, J., LIU, L., CHEUNG, S. W. Compact quasi-selfcomplementary antenna for portable UWB applications. Microwave and Optical Technology Letters, 2014, vol. 56, no. 6, p. 1317-1323. DOI: $10.1002 /$ mop.28317

[11] ABBOSH, A. M. Miniaturization of planar ultrawideband antenna via corrugation. IEEE Antennas and Wireless Propagation Letter, 2008, vol. 7, p. 685-688. DOI: 10.1109/LAWP.2008.2009323

[12] SUN, M., ZHANG, Y. P., LU, Y. Miniaturization of planar monopole antenna for ultrawideband radios. IEEE Transactions on Antennas and Propagation, 2010, vol. 58, no. 7, p. 2420-2425. DOI: $10.1109 /$ TAP.2010.2048851

[13] RADIOM, S., ALIAKBARIAN, H., VANDENBOSCH, G. A. E., et al. An effective technique for symmetric planar monopole antenna miniaturization. IEEE Transactions on Antennas and Propagation, 2009, vol. 57, no. 10, p. 2989-2996. DOI: 10.1109/TAP.2009.2028620

[14] MOBASHSHER, A. T., ABBOSH, A. Utilizing symmetry of planar ultra-wideband antennas for size reduction and enhanced performance. IEEE Antennas and Propagation Magazine, 2015, vol. 57, no. 2, p. 153-166. DOI: 10.1109/MAP.2015.2414488

[15] LIU, J., ESSELlE, K., P., HAY, S. G., et al. Effect of printed UWB antenna miniaturization on pulse fidelity and pattern stability. IEEE Transactions on Antennas and Propagation, 2014, vol. 62 , no. 8, p. 3903-3910. DOI: 10.1109/TAP.2014.2322885

\section{About the Authors ...}

Rajarshi SANYAL has obtained his AMIETE and M.Tech. degree in Electronics and Communication. His area of research includes microstrip antenna and microstrip filters. Presently he is associated with MCKV Institute of Engineering as an Assistant Professor. He has presented 
and published various research papers in national and international journals.

Partha Pratim SARKAR obtained his M.E. and Ph.D. in Engineering from Jadavpur University in the year 1994 and 2002, respectively. He earned his B.E degree in Electronics and Telecommunication Engineering from Bengal Engineering College (presently known as IIEST, Shibpur) in the year 1991. He is presently working as a Professor at the Dept. of Engineering \& Technological Studies, University of Kalyani. His area of research includes microstrip antenna, microstrip filter, frequency selective surfaces, and artificial neural network. He has contributed to numerous research articles in various journals and conferences of repute. He is also a life Fellow of IETE (India) and IE (India).

Santosh Kumar ROY CHOWDHURY obtained his M.E. and Ph.D. in Engineering from Jadavpur University in the year 1968 and 1971, respectively. He earned his B.E degree in Electronics and Telecommunication Engineering from Jadavpur University in the year 1964. He is a Senior member of IEEE, Life fellow of IETE, Fellow of IE, Fellow of West Bengal Academy of Science and Technology. His area of research includes microstrip antenna, microstrip filter, and frequency selective surfaces. He has contributed more than 50 international research articles in various journals and conferences of repute. 